\title{
How do bifidobacteria counteract environmental challenges? Mechanisms involved and physiological consequences
}

\author{
Lorena Ruiz • Patricia Ruas-Madiedo • \\ Miguel Gueimonde · Clara G. de los Reyes-Gavilán • \\ Abelardo Margolles • Borja Sánchez
}

Received: 4 November 2010/Accepted: 26 December 2010/Published online: 13 January 2011

(C) Springer-Verlag 2011

\begin{abstract}
An effective response to stress is of paramount importance for probiotic bifidobacteria administered in foods, since it determines their performance as beneficial microorganisms. Firstly, bifidobacteria have to be resistant to the stress sources typical in manufacturing, including heating, exposure to low water activities, osmotic shock and presence of oxygen. Secondly, and once they are orally ingested, bifidobacteria have to overcome physiological barriers in order to arrive in the large intestine biologically active. These barriers are mainly the acid $\mathrm{pH}$ in the stomach and the presence of high bile salt concentrations in the small intestine. In addition, the large intestine is, in terms of microbial amounts, a densely populated environment in which there is an extreme variability in carbon source availability. For this reason, bifidobacteria harbours a wide molecular machinery allowing the degradation of a wide variety of otherwise non-digestible sugars. In this review, the molecular mechanisms allowing this bacterial group to favourably react to the presence of different stress sources are presented and discussed.
\end{abstract}

Keywords Bifidobacteria - Stress . Technological processes - Gastrointestinal tract

L. Ruiz · P. Ruas-Madiedo · M. Gueimonde .

C. G. de los Reyes-Gavilán · A. Margolles ( $\square)$ · B. Sánchez

Department of Microbiology and Biochemistry of Dairy

Products, Instituto de Productos Lácteos de Asturias, Consejo

Superior de Investigaciones Científicas (IPLA-CSIC), Ctra.

Infiesto s/n, 33300 Villaviciosa, Asturias, Spain

e-mail: amargolles@ipla.csic.es

\section{Introduction}

The human gastrointestinal tract (GIT) harbours a microbial community of great richness and complexity. The total number of intestinal microorganisms represents more than 10 times that of eucaryotic cells in the human body. This complex community constitutes the so-called intestinal microbiota. Different bacterial groups and levels are found throughout the gut, corresponding with the different ecological niches present from mouth to colon. In the sparsely populated small intestine, genera such as Lactobacillus and Bacteroides are considered predominant; while in the heavily populated large bowel, the most frequently found microorganisms include Bacteroides, Clostridium, Fusobacterium, Ruminococcus, Eubacterium and Bifidobacterium. Most people are aware of the presence on the microbiota of potentially detrimental microbes causing health problems (e.g. diarrhoea), but do not know that there are also bacteria naturally present as part of the intestinal microbiota beneficially affecting health. Such beneficial microbes constitute the basis for the use of probiotics and have often been isolated to be included in probiotic products used to improve host health. Indeed, numerous healthpromoting properties have been attributed to certain members of the intestinal microbiota, such as bifidobacteria, and these microorganisms are extensively used as probiotics by the food industry.

Probiotics are defined as live microorganisms which when administered in adequate amounts confer a health benefit on the host [19]. This definition underlines the importance of having a sufficient number of viable microorganisms throughout the entire shelf-life of the product in which they are included. Nevertheless, several reports have indicated a relatively poor survival of probiotic strains during most of the technological processes used 
by the food industry $[11,24,30]$. This has limited the use of probiotics in most food product categories. Therefore, strains with increased stress tolerance would open new opportunities for the development of novel products. Moreover, in addition to technological stress, once they are ingested, probiotics must overcome biological barriers present in the GIT to reach their place of action and exert their beneficial effects. These barriers include digestive enzymes, acidic $\mathrm{pH}$ and bile. Candidate probiotic strains should thus possess traits such as resistance to gastric acidity and bile toxicity. Given the gut origin of most probiotic microorganisms (e.g. bifidobacteria), like other members of the gut microbiota, they must have developed adaptive processes to tolerate these harsh conditions found in the gut.

Several strategies are under investigation to improve probiotic survival, mainly by using pre-exposure to sublethal stresses or selection of derivative strains by stress adaptation. In 1994, it was shown that exposure to sublethal temperatures increases the stress tolerance of Lactobacillus bulgaricus [90]. More recent studies confirm this result, indicating that a stress pre-treatment may increase the survival of probiotics under stress conditions [4, 5, 68]. It is also possible to select stress-tolerant derivatives from originally sensitive strains adaptation [13, 44, 54]. One of the first indications of the selection of derivative Lactobacillus strains with increased thermal-tolerance was reported in the 1950s [51], and there is also recent evidence that selected strains of probiotics can adapt to other industrial stresses [20]. Nevertheless, care should be taken as stress adaptation may alter other probiotic functions. Therefore, understanding the molecular basis of the stress response is a key element not only for the further development of strains with increased stress tolerance but also to know the nature of the modifications in the cell physiology, in order to avoid undesirable changes in the strain properties.

In recent years, different authors have studied the molecular response of probiotic bacteria to stress and some genes have been identified [16, 94]. Proteomic approaches have also been used to this end [5, 57, 72, 73]. This manuscript aims to review the characteristics of the response of bifidobacteria to both technological and gastrointestinal stresses, as well as the different options to improve stress tolerance (Fig. 1).

\section{Response to technological stresses}

The preparation of probiotic formulas in large-scale for oral delivery, either in pharmaceutical preparations or in food carriers, involves the utilization of several technologies that could affect the viability and functionality of these bacteria.
For the generation of a functional probiotic ingredient, dried formats such as freeze-drying and spray-drying are very attractive [48]. However, these technologies expose the bacterial cultures to extreme conditions mainly dealing with temperature and presence of oxygen [10, 88]. Additionally, when probiotics are added as ingredients into food formulations, the type of food matrix and presence of other live microorganisms, as well as the processing technologies and food storage conditions, must be carefully taken into account. Traditionally, fermented dairy products are considered the best carriers for probiotic delivery [75], but other food matrices are also suitable approaches to keep probiotic functionality such as vegetable and cereal beverages among others [59, 62]. Conventional food processing uses heat treatments to preserve the safety and quality of raw materials. But emerging strategies (high pressure, pulsed electric fields, ultrasound, etc.) are under consideration to be implemented in the processing of functional foods, which could present new challenges for probiotic microorganisms [33]. Thus, current food processing submits bacteria to heat, mechanical and aeration stresses, as well as to an acidic environment resulting from the metabolic activity of other microorganisms or the food matrix composition. Some of these challenges are still present during the shelf-life of functional foods, which are stored under refrigerated conditions; therefore, cold shock is an additional stress.

From a technological point of view, bifidobacteria are not robust microorganisms. They are strict anaerobes and only a few species, such as Bifidobacterium animalis subsp. lactis, Bifidobacterium boum, Bifidobacterium thermophilum, Bifidobacterium dentium and Bifidobacterium psychraerophilum, can tolerate a microaerophilic environment $[32,41,87,101]$. In general, their optimal growth temperature ranges between $36-38^{\circ} \mathrm{C}$ and $41-43^{\circ} \mathrm{C}$ for human and animal origin strains, respectively, although B. thermacidophilum is able to grow at $49^{\circ} \mathrm{C}$ and B. psycraerophilum at $4^{\circ} \mathrm{C}$. The optimal growth $\mathrm{pH}$ is around neutrality (6.5-7.0), but $B$. animalis and $B$. thermacidophilum survive well at $\mathrm{pH} 3.5-4.0$ [18, 46, 87]. From these values, it is clear that a tight range of oxygen, temperature and acidic conditions is compatible with bifidobacterial life. However, some bifidobacteria are able to survive under more extreme conditions (e.g. B. animalis subsp. lactis strains), while others display a low tolerance to stress (e.g. some Bifidobacterium bifidum and Bifidobacterium longum strains), although the physiology beyond their adaptation is far from being understood. The mechanisms most extensively studied in response to technological stress of bifidobacteria are those related to heat, oxygen and acid stress. The last one will be reviewed in Sect. "Response to gastrointestinal stress factors", since it is also one of the main barriers that these microorganisms must overcome to survive the gastric transit. 

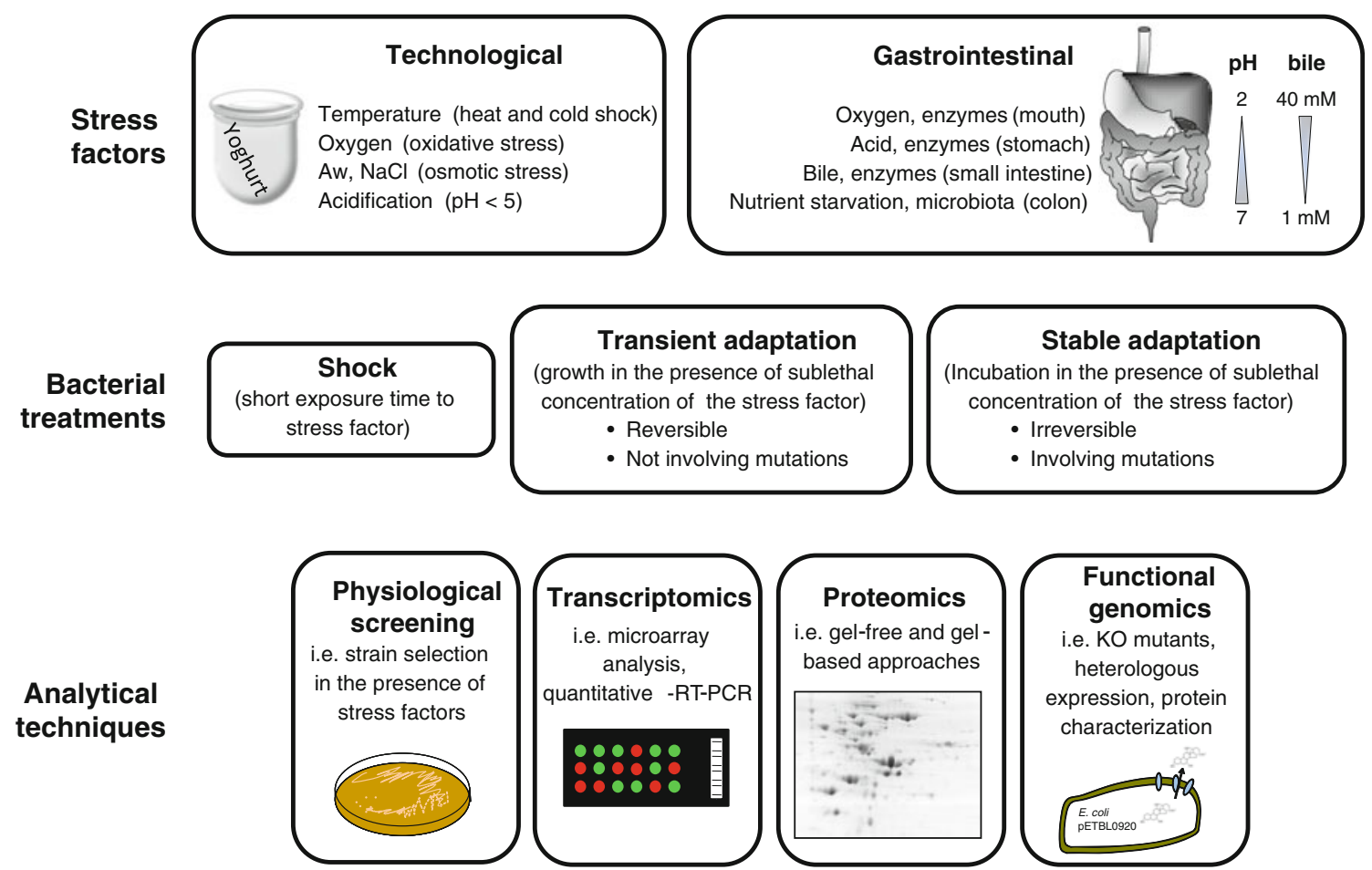

Fig. 1 Schematic representation summarizing the different stress sources, stress treatments and the techniques employed for the study of their effects on bifidobacteria. Upper panel, stress sources can be classified into two groups, technological or gastrointestinal. Middle panel, relating to the duration of the treatment, a short exposure, cell growth for a given time, or long-time exposure to the stress may lead to a stable (or transient) phenotype of resistance. Lower panel, different strategies used to study stress responses in Bifidobacterium strains

\section{Oxygen}

Oxidative damage is related to the production of reactive oxygen species. From the results of scarce studies dealing with the oxygen detoxifying mechanisms in bifidobacteria, it seems that oxygen tolerance could be related to the presence of some enzymes and also to modifications in morphology and cell surface components. The anti-oxidative enzymes catalase and superoxide dismutase seem not to be involved in the aerotolerance of Bifidobacterium. However, the detoxification of hydrogen peroxide by means of NADH oxidative enzymes might play a key role improving bifidobacteria survival under oxygen [86]. Besides, in presence of oxygen, B. longum increases its lag growth phase and morphological changes became apparent (long size and rough surface) associated with changes in the fatty acid profile (shortened chains) and induction of the synthesis of some proteins (Osp proteins) [1]. Variations in surface hydrophobicity, in relation to a reduction in the carbohydrate levels and an increase in protein content detected by FT-IR spectroscopy, were reported as well in B. animalis subsp. lactis Bb12 in presence of oxygen [84].
Heat

Heat shock (HS) is the most studied technological stress in the Bifidobacterium genus. In response to this challenge, several HS proteins, such as chaperons, proteins related to DNA and RNA synthesis and cell division, are increased, this being a mechanism conserved in several species such as B. longum, Bifidobacterium adolescentis and Bifidobacterium breve. This is the case of the chaperon DnaK which is induced at transcriptional level by increasing temperatures [82]. Most investigations into HS response and adaptation have been performed in $B$. longum NCC2705 and $B$. breve UCC2003, taking advantage of the knowledge of its genome sequence and using advanced molecular tools. The global transcriptomic analysis of B. longum $\mathrm{NCC} 2705$ exposed to HS treatment $\left(50^{\circ} \mathrm{C}\right.$ for 3 , 7 and $12 \mathrm{~min}$ ) showed an alteration of expression in $46 \%$ of the genes [60]. Induction of chaperon systems (DnaK, GroEL and HtrA) was previously reported in this species by proteomic approaches [80]. Additionally, strain NCC2705 also responded to HS by inducing the $\operatorname{smpB}$ gene, coding the tmRNA-associated small protein B. Thus, 
the trans-translation machinery is up-regulated with a high constitutive expression of tmRNA gene [60]. For this strain, couples of wild (parental) and derivative (heat adapted) strains could be compared. The HS-derivative NCC2912 was obtained from B. longum NCC2705, and the proteomic analysis of both strains showed quantitative differences in the relative abundance of 19 common proteins. These proteins were involved in glucose metabolism and protein synthesis, and some HS proteins, previously identified by other authors, were also detected [28, 80]. The induced HS proteins were chaperons and proteases, mainly ClpC, ClpA/B, GrpE, DnaK and fk506-binding protein [28]. Regarding DnaK chaperon, it has recently been shown that its up-regulation by HS is due to mutations in $h s p R$ gene, coding for the negative regulator of dnaK operon. The mutations affect its capability for binding to the dnaK promoter, thus rending an overexpression of DnaK [8]. The differences between these two wild-type and HS-derivative B. longum proteomes and transcriptomics reveal a HS-resistance pattern that could reflect the metabolic adaptation to heat stress.

Regarding the HS response of $B$. breve, it is clear that chaperones play a predominant role. Ventura and coworkers demonstrated that the molecular response to heat takes place, in the strain UCC2003, with an over-expression of two groups of chaperones. The first group, composed of the proteins GroEL, GroES, ClpC and ClpPs, is involved in the response to moderate heat shock, whereas the second (DnaK, GrpE, DnaJ and ClpB) is associated with more severe increases in the processing temperatures [94]. In addition, the gene $h s p 20$, coding for a member of the small heat-shock protein family, has been shown to be highly over-expressed after heat shock [95].

\section{Microbial competition}

Another technological challenge that needs to be addressed is the simultaneous presence of two or more microorganisms in the food matrix. The competition for nutrients and the production of antimicrobial metabolites, mainly organic acids, could affect the microbial growth and functionality. In this way, Ruiz and co-workers [66] observed by means of two-dimensional electrophoresis (2DE) that 16 proteins changed their expression in $B$. longum and $B$. breve when grown simultaneously in compartmentalized co-culture in comparison with monocultures. These included ribosomal proteins and those involved in carbohydrate metabolism, gene regulation, cell envelope biogenesis and transport. Thus, it is clear that the physiology of probiotics could be affected when they are added in combination with other probiotic or starter cultures.

\section{Response to gastrointestinal stress factors}

Bifidobacteria display a set of mechanisms in order to overcome the adverse situations encountered through the human GIT and transiently colonize this competitive environment. This section gives an overview on how these microorganisms surmount these difficulties, the processes involved in its response and tolerance to those factors, and the most recent insights into the field. The main molecular mechanisms and gene/protein players are summarized in the Table 1, and some of them are represented in Fig. 2.

Acid $\mathrm{pH}$

Orally administered bifidobacteria firstly experience severe acidic conditions in the stomach, where the $\mathrm{pH}$ is close to 2 , and this strongly compromises bacteria viability. In general, bifidobacteria tolerance to acid is reduced with the exception of $B$. animalis [34, 45]. Isolation of strains with good acid tolerance is desirable, since it is usually related to cross-resistance to some other stress factors, either those characteristic of the intestinal environment or typical of technological processes [13, 79].

A common bacterial response to acidic conditions is the so-called acid tolerance response (ATR), in which acid adaptation is achieved through an assemblage of inducible molecular mechanisms [14, 15, 70]. ATR is induced in bifidobacteria after the exposure of cells to sublethal acidic conditions, enhancing its survival to more severe exposures [47]. $\mathrm{pH}$ resistant bifidobacteria strains with stable phenotype have also been isolated after long exposure to acid $\mathrm{pH}$ [13]. This stable phenotype was related to changes in the surface properties of the strains, such as better adherence to mucin or pathogen displacement [13].

Up to date, only one comparative study, in which an acid $\mathrm{pH}$ resistant $B$. longum strain and its parental (acid $\mathrm{pH}$ sensitive) strain were compared, has been performed [72]. In this work, the two main cytoplasmic subunits of the $\mathrm{F}_{0} \mathrm{~F}_{1}$-ATPase (atpA and atpD) were pointed out to be overrepresented on $2 \mathrm{DE}$ patterns after acid exposure, providing a key role of this enzyme in the Bifidobacterium ATR. The activity of this enzyme was also higher in membranes of B. animalis subsp. lactis grown under acidic conditions [74]. This multimeric enzyme is responsible for the active extrusion of protons that acidify the bacterial cytoplasm under acidic conditions and is directly related to the acid resistance of a given strain [46]. $\mathrm{F}_{0} \mathrm{~F}_{1}$-ATPase contains eight subunits coded in an operon that is organized in two groups, each of them coding for each of the subunits $\left(\mathrm{F}_{0}\right.$, membrane subunit and $\mathrm{F}_{1}$, cytoplasmic subunit). Ventura and co-workers established that the $\mathrm{F}_{0} \mathrm{~F}_{1}$-ATPase operon is transcribed in two different mRNAs, the 
Table 1 Main strategies of response of bifidobacteria to different stress factors

\begin{tabular}{|c|c|c|}
\hline Stress source & Strategy of response & Molecular mechanisms/players \\
\hline \multirow[t]{3}{*}{ Heat shock } & Proper protein folding & Molecular chaperones: GroEL, GroES, GrpE, DnaJ, DnaK, ClpB, Hsp20 \\
\hline & Degradation of misfolded proteins & Proteases: ClpC, ClpP \\
\hline & Regulatory network & Transcriptional regulators: HrcA, HspR, ClgR \\
\hline \multirow[t]{4}{*}{ Acid $\mathrm{pH}$} & Proton extrusion & $\mathrm{F}_{1} \mathrm{~F}_{0}$-ATPase \\
\hline & Cytoplasm buffering/ammonia production & Branched-chain amino acid production \\
\hline & & Glutamine synthetase \\
\hline & Unknown & CysD, MetE \\
\hline \multirow[t]{10}{*}{ Bile salts } & Bile salt/acid detoxification & Multidrug transporters and bile efflux pumps (BetA, Ctr) \\
\hline & Bile salt deconjugation (unclear) & Bile salt hydrolase \\
\hline & Alteration of cell surface & Production of extracellular exopolysaccharides \\
\hline & & Changes in fatty acid composition \\
\hline & & $\begin{array}{l}\text { Changes in surface-associated proteins: enolase, oligopeptide binding } \\
\text { proteins }\end{array}$ \\
\hline & Changes in energetic metabolism & Increase in ATP synthesis \\
\hline & & Changes in the ratios of final glycolytic products \\
\hline & Modification of redox status & Methionine synthetase? Peroxidase? \\
\hline & Proper protein folding & Molecular chaperones: ClpB, HtrA, GrpE, GroES, GroEL, DnaK \\
\hline & Degradation of misfolded proteins & Proteases: ClpC \\
\hline Antimicrobials & Cytoplasm detoxification & Efflux pumps \\
\hline $\begin{array}{l}\text { Carbon source } \\
\text { fluctuations }\end{array}$ & $\begin{array}{l}\text { Ability of degrading a high range of } \\
\text { carbohydrates }\end{array}$ & $\begin{array}{l}\text { Extracellular oligosaccharide-binding proteins, glycosydases and } \\
\text { transcriptional regulators }\end{array}$ \\
\hline
\end{tabular}

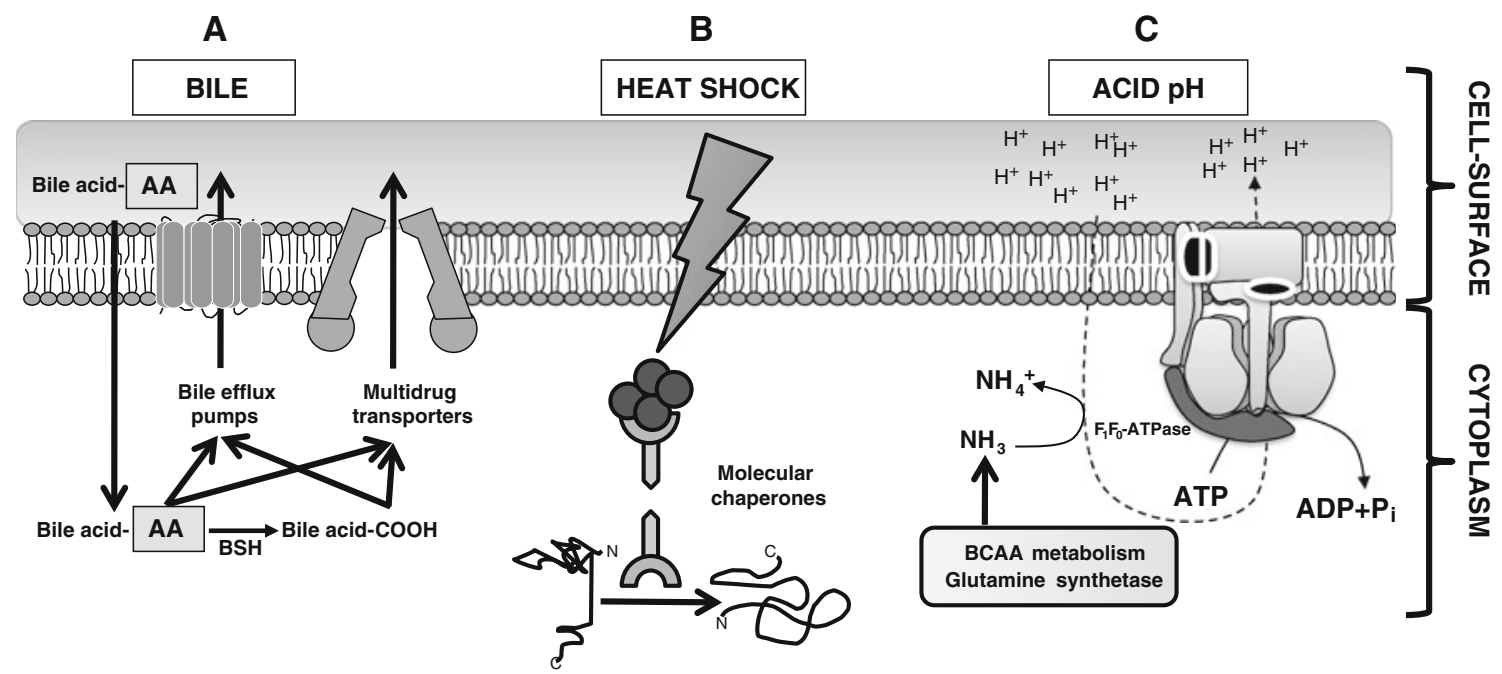

Fig. 2 Main molecular mechanisms involved in the response of bifodobacteria to different stresses. a Bile is detoxified from the cytoplasm by the activity of bile efflux pumps and/or multidrug transporters. Conjugated bile acids are deconjugated by the bile salt hydrolase (BSH), although the relationship of this enzyme with the resistance to bile is unclear. b Finally, both bile and heat shock induce

production of both of them being induced under acidic conditions [93].

ATR in B. longum has been associated with deep reorganizations affecting the level of glycolytic enzymes involved in the metabolism of complex carbohydrates. protein aggregation and misfolding, which is counteracted by the action of chaperones and proteases. $\mathbf{c}$ The $\mathrm{F}_{1} \mathrm{~F}_{0}$-ATPase is used by bifidobacteria for counteracting the cytoplasm acidification that occurs in acidic environments. In addition, production of branchedchain amino acids is coupled with glutamine deamination, rendering ammonia that acts as a cytoplasmic buffer

In addition, the branched-chain amino acid metabolism was also connected to ATR. Specifically, a higher concentration of glutamine synthetase and enzymes involved in branched amino acid synthesis was detected under acidic conditions in B. longum. This proteomic data, together with some 
physiological results [72], are in agreement with the hypothesis formulated by Len and co-workers [39], where the increase in branched-chain amino acids and ammonia production are coupled through the enzyme glutamine synthetase. The ammonia released would capture protons, acting as a cytoplasmic buffer [92]. Finally, ATR in B. longum also involved stable changes in the production of enzymes implied in sulphur amino acid metabolism [72] although, to date, it still remains unclear whether those changes are associated to the ATR.

\section{Bile salts}

Bile is the second biological barrier that probiotic bifidobacteria have to overcome after being ingested. Bile acids and salts are the main components of the bile flow [7], determining its antimicrobial and detergent-like properties. Bile acids are weak organic acids that can passively enter the bifidobacteria cytoplasm [37]. This passive accumulation of deconjugated bile acids has a deep impact on the metabolic processes and homeostasis of the cell, causing leakage of ions and other cellular components, and leading finally to cell death. In particular, bile acids are more toxic than conjugated bile salts (taurine or glycine conjugates), since the latter need specific transporters to be taken up by bacteria [54]. Bile tolerance is very dependent on the species within the genus Bifidobacterium. However, bifidobacteria can develop stable bile resistance phenotypes as a response to bile exposure, regardless of its intrinsic tolerance [77], and often this process involves the appearance of cross-resistance to other stress factors [74]. Additionally, adaptation to bile has been related to changes in carbohydrate metabolic profiles [44, 54, 64], changes in lipid and protein composition of membranes [44, 67], in the ability to compete with enteropathogens [26, 27] and in the antibiotic resistance patterns, among others [34, 52].

The structure and composition of the bacterial surface have a profound influence on bile tolerance. More concisely, lipid composition, membrane protein profiles and cell wall functionality play key roles in the response to bile in the genus Bifidobacterium [22, 44, 67]. Production of extracellular polysaccharides (exopolysaccharides; EPSs) is also a mechanism mediating protection against bile in this genus [3, 63], and a direct correlation has recently been established between EPS production and bile tolerance in Bifidobacterium spp. [3]. Furthermore, bile decreases the concentration of several enzymes involved in fatty acid and phospholipid synthesis in B. animalis subsp. lactis [21,73], those observations being in accordance with previous findings related to the induction of changes in membrane composition of bifidobacteria [36, 37, 67]. These changes in the lipid composition of the membranes are thought to reduce the bile salt diffusion rate to the cytoplasm, thus contributing to bile tolerance. In the case of surface-associated proteins, such as adhesins, some of them are overproduced as a response to bile, and they may enhance the colonization of the human gut, although this statement is merely speculative $[9,35,65]$.

The cell membrane is one of the main targets of bile, and cells can be detoxified from bile salts by the action of efflux pumps. In the particular case of bifidobacteria, two bile efflux pumps have been described up to date, Ctr and BetA, being directly related to bile resistance through a bile extrusion activity [25, 58]. Interestingly, the gene coding for BetA has been shown to be under the control of a bileinducible promoter, guaranteeing in this way its expression in the human intestine, where bile salts are present.

Remarkably, particular responses to bile seem to be species dependent $[71,73,77]$. While most of the enzymes of the glycolysis were overrepresented upon bile exposure in B. longum, xylulose-5-phosphate/fructose-6-phosphate phosphoketolase and glyceraldehyde-3-phosphate dehydrogenase were the only enzymes of this pathway overrepresented in B. animalis. This observation was correlated to glucose consumption, increased in $B$. longum but not in $B$. animalis, in response to bile.

Oxidative damage is another harmful effect of bile salts on the cells [55]. Among the mechanisms employed by bifidobacteria in order to deal with such damage, induction of proteins involved in SOS response, including a thioredoxin-dependent thiol peroxidase, is noticeable [73]. Adaptation to bile salts in $B$. animalis was also related to changes in methionine biosynthesis enzymes, thus suggesting methionine metabolism (whose sulphur group is susceptible to oxidization) and regulation of redox state of the cells are crucial for regulation of oxidative stress [29, 77].

Other groups of proteins whose production were affected by the presence of bile salts were chaperones and proteases, overproduced in order to conduct proper folding of proteins, and to promote a quicker recycling of misfolded and aggregated proteins [31]. In this regard, a complete set of chaperones has been revealed to be overexpressed in Bifidobacterium in response to bile exposure or adaptation, among which are $\mathrm{ClpB}$, GrpE, HtrA, GroEL, GroES and DnaK [71, 73, 80].

Finally, it is noteworthy to highlight that bile adaptation in $B$. animalis was related to a constitutive increase in the production and activity of the enzyme bile salt hydrolase (BSH) $[53,73]$. BSH is responsible for bile salt deconjugation, but its role in the response to bile is, to date, unclear [23]. However, this observation suggests some role of BSH in bile adaptation, although its expression does not seem to be regulated by bile. On the contrary, in vivo assays have demonstrated an intracellular accumulation of BSH in B. longum in the GIT of rabbits, suggesting that intestinal factors different from bile could trigger BSH expression [104]. 
Carbon source availability

Fluctuation in carbon source availability in the gut is an important factor conditioning the balance of microbial groups within the human intestinal microbiota. Bifidobacteria are, in this regard, very well adapted to these fluctuations, displaying a high metabolic versatility allowing utilization of different carbon sources. In silico analysis of the available Bifidobacterium genomes has revealed the presence of an extensive battery of genes potentially involved in carbohydrate transport and metabolism, including a broad arsenal of glycosidases. The simultaneous bioactivity of these enzymes allows bifidobacteria to metabolize from galactomannan-rich plant gums to human milk oligosaccharides (HMOs) and glycans from mucin [6, 83, 91]. Remarkably, B. longum subsp. infantis genome contains the largest amount of genes coding for predicted extracellular oligosaccharide-binding proteins (21 copies) versus, for instance, the 10 or 11 present in the genomes of B. longum subsp. longum or B. adolescentis, respectively. In this context, there is evidence for genetic duplication in the origin of some carbohydrate utilization clusters. This fact reflects the strong selective pressure to which B. longum genomes are exposed, in order to obtain a high carbohydrate catabolic diversity and thus increase their fitness in the GIT environment [83].

Overall, the broad diversity of carbohydrate metabolism activities coded in Bifidobacterium genomes agrees with the high carbohydrate transport and metabolism genes overrepresentation in human gut microbiomes [38, 40], which reflects the importance of those gene categories in adaptation to the intestinal environment [43]. All this catabolic machinery, allowing bifidobacteria to quickly adapt to the wide substrate fluctuations occurring at the intestinal level, seem to be orchestrated by the action of the large percentage of transcriptional repressors encoded in their genomes $[6,81,83,91]$.

\section{Improving the robustness of bifidobacteria}

Different Bifidobacterium strains may show big differences in their tolerance to technological and physiological stresses; therefore, the identification of strains showing greater tolerance among those presenting suitable probiotic properties is important for granting the efficacy of probiotic microorganisms included in food products. Several production and culture conditions, i.e. the presence of certain single sugars, can contribute to increase the tolerance of bifidobacteria to stress factors [53, 56]. Organic matrices, in some cases combined with prebiotics, have been employed in cell-entrapment techniques (e.g. microencapsulation) to improve the viability of bifidobacteria in foods or through the gastrointestinal transit [17, 50, 89]. The addition of protectors and supplements can be used with the same purpose $[69,78]$. In this respect, milk, or milkderived preparations, has been shown to act as effective protectors of bifidobacteria during simulated gastrointestinal digestions, thus increasing their survival in physiologically stressful conditions [3, 76]. Skimmed milk powder protects bifidobacteria during freeze-drying and spraydrying procedures used in the industry for preparing concentrated microbial cultures and facilitates the rehydration of the dried preparation [12, 49].

Apart from external factors helping bacteria to cope with unfavourable environmental conditions, the improvement of the stress tolerance of the microorganism itself constitutes one of the main targets of the current research in bifidobacteria. In this regard, stress adaptation and gene modification are important areas of research.

Variations in stress tolerance have been documented for bifidobacteria and stress-resistant mutants sometimes arise spontaneously [13, 42]. Exposure of bifidobacteria to sublethal stress factors is a relatively easy way to increase the appearance of such stress-resistant mutants. These derivatives usually present a stable stress-resistant phenotype, with changes affecting not only the targeted property but often also triggering other pleiotropic changes and presenting cross-resistance to other stresses and alteration of other physiological features [54, 77]. Functional properties should then be re-assessed in these new strains when they are intended for probiotic or technological use.

In general, the resistance of bifidobacteria to acidic $\mathrm{pH}$ is poor, with the exception of $B$. animalis [45, 61], which could partially explain the good survival rate of this species through the human GIT $[2,61]$. However, it has been found that acquisition of resistance to bile implies a concomitant increase in resistance to low $\mathrm{pH}$ and vice versa, adaptation to low $\mathrm{pH}$ is associated with a bile resistance phenotype $[72,74]$. The most relevant feature that links bile and acid adaptation seems to be the extrusion of protons from the cytoplasm through the activity of the membrane $\mathrm{F}_{1} \mathrm{~F}_{0^{-}}$ ATPase [74]. In fact, the induction of the $\mathrm{F}_{0} \mathrm{~F}_{1}$-ATPase seems to be very important for maintaining the viability of bifidobacteria under GIT conditions [74].

Regarding technological stresses, it is worth mentioning that heat-tolerant mutants of B. longum have been obtained by successive sublethal heat-shock treatments. The genetic bases of such adaptation have been characterized recently [8, 60, 80]), and a few Bifidobacterium derivative strains able to grow aerobically have also been reported [41, 103]. These adapted strains represent a promising option for the functional food industry.

Improvement of the stress tolerance can also be obtained by gene modification. This strategy was used to increase $B$. breve [85] tolerance to acidic and high osmolar 
Fig. 3 Schematic representation of the stress gene regulatory network proposed for B. breve UCC2003. Dotted lines indicate the predicted interaction, and closed lines indicate a proven interaction. A dash at the end of a line indicates repression, while a triangle at the end of a line indicates activation.

Connections between the various regulons occur at different levels, which is indicative of complex interactions. [Reproduced with ASM press permission, Copyright 2009; from [105]

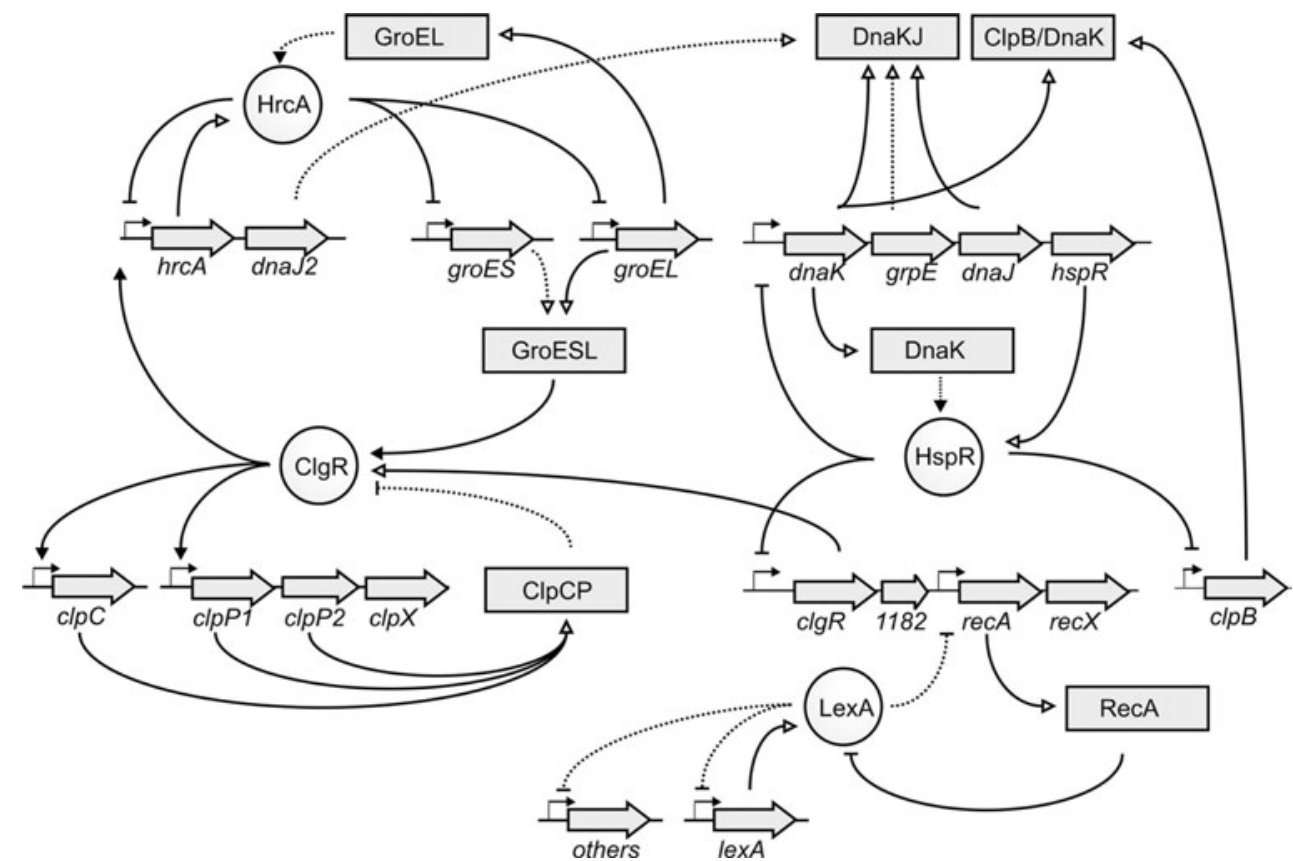

conditions mimicking the gut environment by cloning the listerial betaine uptake system, BetL, into the probiotic strain $B$. breve UCC2003. A similar approach was followed to increase bile resistance in the same strain by heterologous expression of the L. monocytogenes bile resistance mechanism BilE [102]. An improvement of gastric transit and of intestinal persistence was obtained with both strains following oral administration to mice; additionally mice fed the recombinant strains showed reduced oral infections by Listeria monocytogenes. In spite of that the introduction of genes from pathogens into probiotic strains is unlikely to meet with immediate approval from regulatory food authorities.

\section{Regulation of the stress response}

The response of bifidobacteria to the different environmental challenges is a multifactorial process involving the action of several mechanisms and cellular pathways. In the general response to stress, chaperones hold a prevailing place. Chaperones are a subset of proteins involved in both the correct folding of proteins and in the enzymatic degradation of misfolded proteins, two common (and negative) effects promoted by stress. Firstly described as heat-shock proteins (HSPs), molecular chaperones include GroEL (HSP60), DnaK (HSP70), ClpB (HSP100), and proteases such as $\mathrm{ClpC}$ and ClpP, among others [94].

Regulation of stress response has been studied in detail in $B$. breve UCC2003, and it has been shown that different groups of chaperons are affected depending on the regulators involved. For instance, during HS the regulation of $c l p \mathrm{C}$ and $c l p \mathrm{P}$ genes is dependent on the product of the gene $c \lg \mathrm{R}$, a transcriptional activator that requires the presence of the protein GroEL as cofactor [98, 100]. On the contrary, genes groEL and groES are regulated by the repressor protein HrcA [96]. The other group of chaperones is basically regulated by the repressor HspR [97, 99]. This chaperone accumulation following HS has been confirmed by studies involving high-throughput techniques, such as DNA arrays or 2DE $[60,80]$.

Recently, the work by Zomer and colleagues has shed some light on how the response to different stresses may overlap. Indeed, the molecular regulation of chaperone induction appears to constitute a general molecular mechanism of stress response in Bifidobacterium, depending, in turn, on the accumulation of misfolded proteins [105]. In the genus Bifidobacterium, and in general in the Actinobacteria taxa, the genes coding for chaperones are arranged in operons, which are subjected to tight genetic regulation, in a sort of regulon. This is dependent on the existence of certain transcriptional regulators, mainly $\mathrm{HrcA}$ (heat regulation at CIRCE), HspR (heat-shock protein repressor) and $\mathrm{ClgR}$ (Clp gene regulator), each of those binding to more or less conserved inverted repeats present in the promoter regions of the above mentioned operons [105]. This regulatory network has been suggested as the paradigm for stress adaptation in bifidobacteria [105] and is represented schematically in Fig. 3. In this network, the different operons containing the different chaperones are regulated by the interaction at different levels of the transcriptional regulators $\mathrm{ClgR}, \mathrm{HrcA}$ and $\mathrm{HspR}$ with chaperones (HrcA with free GroEL, ClgR with GroESL and 
HspR with DnaK) and with the corresponding inverted repeats located in the different promoters. An in-depth explanation to all those processes can be found in Zomer and co-workers [105], and in Ventura and colleagues [94].

\section{Perspectives and future challenges}

The selection of bifidobacteria strains for being included in functional foods has traditionally been carried out mainly taking into account phenotypical aspects related to their appropriate technological performance, and their ability to survive the harsh conditions of the human GIT, without paying much attention to the mechanisms responsible for stress tolerance, which is largely unexplored at molecular level. However, during the last decade detailed physiological analyses, supported by functional genomics and proteomics data, shed some light on the molecular processes used by bifidobacteria to counteract environmental challenges, as well as in the mechanisms of stress sensing, gene regulation and adaptive behaviour of this bacterial group. Future and ongoing research in this field must take advantage of the enormous amount of data generated from bacterial genome projects and human microbiome projects. This will facilitate the understanding of the specific effects of probiotics, the processes involved in survival and the crosstalk mechanisms with the human host. Also, research on stress response might help to generate improved specific strain properties by building robust stress resistance phenotypes that prepare these microorganisms to cope with adverse conditions. Such data will also enable us to know which factors influence the performance of bifidobacteria, thus allowing a rational approach to strain improvement and, in turn, provide information about the functional properties of probiotics.

Acknowledgments Borja Sánchez was the recipient of a Juan de la Cierva postdoctoral contract from the Spanish Ministerio de Ciencia e Innovación (MICINN), and Lorena Ruiz was supported by an I3P predoctoral contract granted by CSIC and FEDER funds. Research in our group is supported by grants AGL2007-61805, AGL2007-62736 and RM2010-00012-00-00, from MICINN.

\section{References}

1. Ahn JB, Hwang HJ, Park JH (2001) Physiological responses of oxygen-tolerant anaerobic Bifidobacterium longum under oxygen. J Microbiol Biotechnol 11:443-451

2. Alander M, Matto J, Kneifel W, Johansson M, Kogler B, Crittenden R, Mattila-Sandholm T, Saarela M (2001) Effect of galacto-oligosaccharide supplementation on human faecal microflora and on survival and persistence of Bifidobacterium lactis $\mathrm{Bb}-12$ in the gastrointestinal tract. Int Dairy J 10:817-825

3. Alp G, Aslim B (2010) Relationship between the resistance to bile salts and low $\mathrm{pH}$ with exopolysaccharide (EPS) production of Bifidobacterium spp isolated from infants feces and breast milk. Anaerobe 16:101-105

4. Ananta E, Knorr D (2004) Evidence on the role of protein biosynthesis in the induction of heat tolerance of Lactobacillus rhamnosus GG by pressure pre-treatment. Int J Food Microbiol 96:307-313

5. Anastasiou R, Leverrier P, Krestas I, Rouault A, Kalantzopoulos G, Boyaval P, Tsakaliodou E, Jan G (2006) Changes in protein synthesis during thermal adaptation of Propionibacterium freudenreichii subsp shermanii. Int J Food Microbiol 108: 301-314

6. Ashida H, Miyake A, Kiyohara M, Wada J, Yoshida E, Kumagai H, Katayama T, Yamamoto K (2009) Two distinct $\alpha$-L-fucosidases from Bifidobacterium bifidum are essential for the utilization of fucosylated mil oligosaccharides and glycoconjugates. Glycobiology 19:1010-1017

7. Begley M, Gahan CG, Hill C (2005) The interaction between bacteria and bile. FEMS Microbiol Rev 72:1729-1738

8. Berger B, Moine D, Mansourian R, Arigoni F (2010) HspR mutations are naturally selected in Bifidobacterium longum when successive heat shock treatments are applied. J Bacteriol 192:256-263

9. Candela M, Bergmann S, Vici M, Vitali B, Turroni S, Eikmanns BJ, Hammerschnidt S, Brigidi P (2007) Binding of human plasminogen to Bifidobacterium. J Bacteriol 189:5929-5936

10. Carvalho AS, Silva J, Ho P, Teixeira P, Malcata FX, Gibbs P (2004) Relevant factors for the preparation of freeze-dried lactic acid bacteria. Int Dairy J 14:835-847

11. Charteris WP, Kelly PM, Morelli L, Collins JK (1998) Development and application of an in vitro methodology to determine the transit tolerance of potentially probiotic Lactobacillus and Bifidobacterium species in the upper human gastrointestinal tract. J Appl Microbiol 84:759-768

12. Chavez BE, Ledeboer AM (2007) Drying of probiotics: optimization of formulation and process to enhance storage survival. Drying Technol 25:1193-1201

13. Collado MC, Sanz Y (2006) Method for direct selection of potentially probiotic Bifidobacterium strains from human feces based on their acid-adaptation ability. J Microbiol Meth 66:560-563

14. Cotter PD, Hill C (2003) Surviving the acid test: responses of gram-positive bacteria to low $\mathrm{pH}$. Microbiol Mol Biol Rev 67:429-453

15. Davis MJ, Coote PJ, O'Byme CP (1996) Acid tolerance in Listeria monocytogenes: the adaptive acid tolerance response (ATR) and growth-phase dependent acid resistance. Microbiology-SGM 142:2975-2982

16. De Angelis M, Di Cagno R, Huet C, Crecchio C, Fox PF, Gobbetti M (2004) Heat shock response in Lactobacillus plantarum. Appl Environ Microbiol 70:1336-1346

17. Dink WK, Shah NP (2009) Effect of various encapsulating materials on the stability of probiotic bacteria. J Food Sci 74:M1000-M1077

18. Dong X, Xin Y, Jian W, Liu X, Ling D (2000) Bifidobacterium thermacidophilum $\mathrm{sp}$ nov isolated from an anaerobic digester. Int J System Evol Microbiol 50:119-125

19. FAO/WHO (2002) Guidelines for the evaluation of probiotics in food food and health. Agricultural Organization of the United Nations and World Health Organization working group report

20. Fiocco D, Capozzi V, Goffin P, Hols P, Spano G (2007) Improved adaptation to heat, cold and solvent tolerance in Lactobacillus plantarum. Appl Microbiol Biotechnol 77:909-915

21. Garrigues C, Stuer-Lauridsen B, Johansen E (2005) Characterisation of Bifidobacterium animalis subsp lactis Bb12 and other probiotic bacteria using genomics, transcriptomics and proteomics. Aust J Dairy Tecnhol 60:84-92 
22. Gómez-Zavaglia A, Kociubinski G, Pérez P, Disalvo E, de Antoni G (2002) Effect of bile on the lipid composition and surface properties of bifidobacteria. J Appl Microbiol 93: 794-799

23. Grill JP, Perrin S, Schneider F (2000) Bile salt toxicity to some bifidobacteria strains: role of conjugated bile salt hydrolase and pH. Can J Microbiol 46:878-884

24. Gueimonde M, Delgado S, Mayo B, Ruas-Madiedo P, Margolles A, de los Reyes-Gavilán CG (2004) Viability and diversity of probiotic Lactobacillus and Bifidobacterium populations included in commercial fermented milks. Food Res Int 37:839-850

25. Gueimonde M, Garrigues C, van Sinderen D, de los ReyesGavilán CG, Margolles A (2009) Bile-inducible efflux transporter from Bifidobacterium longum NCC2705, conferring bile resistance. Appl Environ Microbiol 75:3153-3160

26. Gueimonde M, Margolles A, de los Reyes-Gavilán CG, Salminen S (2007) Competitive exclusion of enteropathogens from human intestinal mucus by Bifidobacterium strains with acquired resistance to bile- A preliminary study. Int $\mathrm{J}$ Food Microbiol 113:228-232

27. Gueimonde M, Noriega L, Margolles A, de los Reyes-Gavilán CG, Salminen S (2005) Ability of Bifidobacterium strains with acquired resistance to bile to adhere to human intestinal mucus. Int J Food Microbiol 101:341-346

28. Guillaume E, Berger B, Affolter M, Kussmann M (2009) Labelfree quantitative proteomics of two Bifidobacterium longum strains. Proteomics 72:771-784

29. Hondrop ER, Matthews RG (2004) Oxidative stress inactivates cobalamin-independent methionine synthase (MetE) in Escherichia coli LR. Plos Biol 2:1738-1753

30. Kailasapathy K, Harmstorf I, Philiphs M (2008) Survival of Lactobacillus acidophilus and Bifidobacterium animalis ssp lactis in stirred fruit yogurts. LWT-Food Sci Technol 41:13171322

31. Kampinga $H$ (2006) Chaperones in preventing protein denaturation in living cells and protecting against cellular stress. Handbook Exp Pharmacol 172:1-42

32. Kawasaki S, Mimura T, Satoh T, Takeda K, Niimura Y (2006) Response of the microaerophilic Bifidobacterium species, $B$ boum and $B$ thermophilum, to oxygen. Appl Environ Microbiol 72:6854-6858

33. Kelly AL, Zeece M (2009) Application of novel technologies in processing of functional foods. Aus J Dairy Technol 64:12-15

34. Kheadr E, Dabour N, Le Lay C, Lacroix C, Fliss I (2007) Antibiotic susceptibility profile of bifidobacteria as affected by oxgall, acid, and hydrogen peroxide stress. Antimicrob Agents Chemother 51:169-174

35. Knaust A, Weber MW, Hammerschmidt S, Bergmann S, Frosch M, Kurzai O (2007) Cytosolic proteins contribute to surface plasminogen recruitment of Neisseria meningitides. J Bacteriol 189:3246-3255

36. Kociubinski G, Zavaglia AG, Perez PF, Disalvo EA, De Antoni GL (2002) Effect of bile components on the surface properties of bifidobacteria. J Dairy Res 69:293-302

37. Kurdi P, Tanaka H, Van Veen HW, Asano K, Tomita F, Yokota A (2006) Mechanisms of growth inhibition by free bile acids in lactobacilli and bifidobacteria. J Bacteriol 188:1979-1986

38. Kurokawa K, Itoh H, Kuwahara T, Oshima K, Toh H, Toyoda A, Takami H, Morita H, Sharma VK, Srivastava TP, Taylor TD, Noguchi H, Mori H, Ogura Y, Ehrlich DS, Itoh K, Takagi T, Sakaki Y, Hayashi T, Hattori M (2007) Comparative metagenomics revealed commonly enriched gene sets in human gut microbiomes. DNA Res 14:169-181

39. Len AC, Harty DW, Jacques NA (2004) Proteome analysis of Streptococcus mutans metabolic phenotype during acid tolerance. Microbiology-SGM 150:1353-1366
40. Ley RE, Hamady M, Lozupone C, Turnbauch PJ, Ramey RR, Bircher JS, Schlegel ML, Tucker TA, Schrenzel MD, Knight R, Gordon JI (2008) Evolution of mammals and their gut microbes. Science 320:1647-1651

41. Li QQ, Chen QH, Hui R, Zhu DS, He GQ (2010) Isolation and characterization of an oxygen, acid and bile resistant Bifidobacterium animalis subsp lactis Qq08. J Sci Food Agric 90: $1340-1346$

42. Lian WC, Hsiao HC, Chou CC (2002) Survival of bifidobacteria after spray-drying. Int J Food Microbiol 74:79-86

43. Lozupone CA, Hamady M, Cantarel BL, Coutinho PM, Henrisat B, Gordon JI, Knight R (2008) The convergence of carbohydrate active gene repertoires in human gut microbes. Proc Natl Acad Sci U S A 105:15076-15081

44. Margolles A, García L, Sánchez B, Gueimonde M, de los ReyesGavilán CG (2003) Characterisation of a Bifidobacterium strain with acquired resistance to cholate-a preliminary study. Int $\mathrm{J}$ Food Microbiol 82:191-198

45. Masco L, Crockaert C, Van Hoorde K, Swings J, Huys G (2007) In vitro assessment of the gastrointestinal transit tolerance of taxonomic reference strains from human origin and probiotic product isolates of Bifidobacterium. J Dairy Sci 90:3572-3578

46. Matsumoto M, Ohishi H, Benno Y (2004) H+ ATPase activity in Bifidobacterium with special reference to acid tolerance. Int $\mathbf{J}$ Food Microbiol 93:109-113

47. Maus JE, Ingham SC (2003) Employment of stressful conditions during culture production to enhance subsequent cold- and acidtolerance of bifidobacteria. J Appl Microbiol 95:146-154

48. Meng XC, Stanton C, Fitzgerald GF, Daly C, Ross RP (2008) Anhydrobiotics: the challenges of drying probiotic cultures. Food Chem 106:1406-1416

49. Modesto M, Mattarelli P, Biavati B (2004) Resistance to freezing and freeze-drying storage processes of potential probiotic bifidobacteria. Ann Microbiol 54:43-48

50. Mokarram RR, Mortazavi SA, Najafi MBH, Shahidi F (2009) The influence of multi-stage alginate-coating on survivability of potential probiotic bacteria in simulated gastric and intestinal juice. Food Res Int 42:1040-1045

51. Niven CF, Buettner LG, Evans JB (1954) Thermal tolerance studies on the heterofermentative lactobacilli that cause greening of cured meat products. Appl Microbiol 2:26-29

52. Noriega L, de los Reyes-Gavilán CG, Margolles A (2005) Acquisition of bile salt resistance promotes antibiotic susceptibility changes in Bifidobacterium. J Food Prot 68:1916-1919

53. Noriega L, Cuevas I, Margolles A, de los Reyes-Gavilán CG (2006) Deconjugation and bile salts hydrolase activity by Bifidobacterium strains with acquired resistance to bile. Int Dairy $\mathbf{J}$ $16: 850-855$

54. Noriega L, Gueimonde M, Sánchez B, Margolles A, de los Reyes-Gavilán CG (2004) Effect of the adaptation to high bile salts concentrations on glycosidic activity, survival at low $\mathrm{pH}$ and cross-resistance to bile salts in Bifidobacterium. Int J Food Microbiol 94:79-86

55. Payne CM, Crowley C, Washo-Stultz D, Briehl M, Bernstein H, Bernstein C, Beard S, Holubec H, Warneke J (1998) The stressresponse proteins poly (ADP-ribose) polymerase and NF-kap$\mathrm{paB}$ protect against bile salt-induced apoptosis. Cell Death Differ 5:623-636

56. Perrin S, Grill JP, Schneider F (2000) Effects of fructooligosaccharides and their monomeric components on bile salt resistance in three species of bifidobacteria. J Appl Microbiol 88:968-974

57. Prasad J, McJarrow P, Gopal P (2003) Heat and osmotic stress responses of probiotic Lactobacillus rhamnosus HN001 (DR20) in relation to viability after drying. Appl Environ Microbiol 69:917-925 
58. Price CE, Reid SJ, Driessen AJ, Abratt VR (2006) The Bifidobacterium longum NCIMB702259T ctr gene codes for a novel cholate transporter. Appl Environ Microbiol 72:923-926

59. Ranadheera RDCS, Baines SK, Adams MC (2010) Importance of food in probiotic efficacy. Food Res Int 43:1-7

60. Rezzonico E, Lariani S, Barretto C, Cuanoud G, Giliberti G, Delley M, Arigoni F, Pessi G (2007) Global transcriptome analysis of the heat shock response of Bifidobacterium longum. FEMS Microbiol Lett 271:136-145

61. Ritter P, Kohler C, von Ah U (2009) Evaluation of the passage of Lactobacillus gasseri $\mathrm{K} 7$ and bifidobacteria from the stomach to intestines using a single reactor model. BMC Microbiol 9:87

62. Rivera-Espinoza Y, Gallardo-Navarro Y (2010) Non-dairy probiotic products. Food Microbiol 27:1-11

63. Ruas-Madiedo P, Gueimonde M, Arigoni F, de los ReyesGavilán CG, Margolles A (2009) Bile affects the synthesis of exopolysaccharides by Bifidobacterium animalis. Appl Environ Microbiol 75:241-259

64. Ruas-Madiedo P, Hernández-Barranco A, Margolles A, de los Reyes-Gavilán CG (2005) A bile salt-resistant derivative of Bifidobacterium animalis has an altered fermentation pattern when grown on glucose and maltose. Appl Environ Microbiol 71:6564-6570

65. Ruiz L, Couté Y, Sánchez B, de los Reyes-Gavilán CG, Sánchez JC, Margolles A (2009) The cell-envelope proteome of Bifidobacterium longum in an in vitro bile environment. Microbiology-SGM 274:316-322

66. Ruiz L, Sánchez B, de Los Reyes-Gavilán CG, Gueimonde M, Margolles A (2009) Coculture of Bifidobacterium longum and Bifidobacterium breve alters their protein expression profiles and enzymatic activities. Int J Food Microbiol 133:148-153

67. Ruiz L, Sánchez B, Ruas-Madiedo P, de los Reyes-Gavilán CG, Margolles A (2007) Cell envelope changes in Bifidobacterium animalis ssp lactis as a response to bile. FEMS Microbiol Lett 274:316-322

68. Saarela M, Rantala M, Hallamaa K, Nohynek L, Virkajarvi I, Matto J (2004) Stationary-phase acid and heat-treatments for improvement of the viability of probiotic lactobacilli and bifidobacteria. J Appl Microbiol 96:1205-1214

69. Saarela MH (2007) Probiotic technology maintaining viability and stability. Agro Food Ind Hi-Tech 18:19-21

70. Samelis J, Ikeda JS, Sofos JN (2003) Evaluation of the $\mathrm{pH}$-dependent stationary-phase acid tolerance in Listeria monocytogenes and Salmonella Typhimurium DT104 induced by culturing in media with $1 \%$ glucose: a comparative study with Escherichia coli O157:H7. J Appl Microbiol 95:563-575

71. Sánchez $B$, Champomier-Vergès MC, Anglade $P$, Baraige $F$, de los Reyes-Gavilán CG, Margolles A, Zagorec M (2005) Proteomic analysis of global changes in protein expression during bile salt exposure of Bifidobacterium longum NCIMB8809. J Bacteriol 187:5799-5808

72. Sánchez B, Champomier-Vergès MC, Collado MC, Anglade $P$, Baraige F, Sanz Y, de los Reyes-Gavilán CG, Margolles A, Zagorec M (2007) Low-pH adaptation and the acid tolerance response of Bifidobacterium longum biotype longum. Appl Environ Microbiol 73:6450-6459

73. Sánchez B, Champomier-Vergès MC, Stuer-Lauridsen B, Ruas-Madiedo P, Anglade P, Baraige F, de los Reyes-Gavilán CG, Johansen E, Zagorec M, Margolles A (2007) Adaptation and response of Bifidobacterium animalis subsp. lactis to bile: a proteomic and physiological approach. Appl Environ Microbiol 73:6757-6767

74. Sánchez B, de los Reyes-Gavilán CG, Margolles A (2006) The F1F0-ATPase of Bifidobacterium animalis is involved in bile tolerance. Environ Microbiol 8:1825-1833
75. Sánchez B, de los Reyes-Gavilán CG, Margolles A, Gueimonde M (2009) Probiotic fermented milks: present and future. Int J Dairy Technol 62:472-483

76. Sánchez B, Fernández-García M, Margolles A, de los ReyesGavilán CG, Ruas-Madiedo P (2010) Technological and probiotic selection criteria of a bile-adapted Bifidobacterium animalis subsp lactis strain. Int Dairy J 20:800-805

77. Sánchez B, Ruiz L, de los Reyes-Gavilán CG, Margolles A (2008) Proteomics of stress response in Bifidobacterium. Front Biosci 13:6905-6919

78. Sanders ME, Marco ML (2010) Food formats for effective delivery of probiotics. Ann Rev Food Sci Technol 1:65-85

79. Sanz Y (2007) Ecological and functional implications of the acid-adaptation ability of Bifidobacterium: a way of selecting improved probiotic strains. Int Dairy J 17:1284-1289

80. Savijoki K, Suokko A, Palva A, Valmu L, Kalkkinen N, Varmanen P (2005) Effect of heat-shock and bile salts on protein synthesis of Bifidobacterium longum revealed by (35S)methionine labelling and two dimensional gel electrophoresis. FEMS Microbiol Lett 248:207-215

81. Schell MA, Karmirantzou M, Snel B, Vilanova S, Berger B, Passi G, Zwahlen MC, Desiere F, Bork P, Delley M, Pridmore $\mathrm{RD}$, Arigoni F (2002) The genome sequence of Bifidobacterium longum reflects its adaptation to the human gastrointestinal tract. Proc Natl Acad Sci U S A 99:14422-14427

82. Schmidt G, Zink R (2000) Basic features of the stress response in three species of bifidobacteria: $B$ longum, $B$ adolescentis and $B$ breve. Int J Food Microbiol 55:41-45

83. Sela DA, Chapman J, Adeuya A, Kim JH, Chen F, Whitehead TR, Lapidus A, Rokhsar DS, Lebilla CB, German JB, Price NP, Richardson PM, Mills DA (2008) The genome sequence of Bifidobacterium longum subsp infantis reveals adaptations for milk utilization within the infant microbiome. Proc Natl Acad Sci U S A 105:18964-18969

84. Shakirova L, Auzina L, Zikmanis P, Gavare M, Grube M (2010) Influence of growth conditions on hydrophobicity of Lactobacillus acidophilus and Bifidobacterium lactis cells and characteristics by FT-IR spectra. Spectros Int J 24:251-255

85. Sheehan VM, Sleator RD, Hill C, Fitzgerald GF (2007) Improving gastric transit, gastrointestinal persistence and therapeutic efficacy of the probiotic strain Bifidobacterium breve UCC2003. Microbiology-SGM 153:3563-3571

86. Shin SY, Park JH (1997) Activities of oxidative enzymes related with oxygen tolerance in Bifidobacterium sp. J Microbiol Biotechnol 7:356-359

87. Simpson PJ, Ross RP, Filzgerald GF, Stanton C (2004) Bifidobacterium psychraerophilum sp nov and Aeriscardovia aeriphila gen nov, sp nov, isolated from a porcine caecum. Int J Syst Evol Microbiol 54:401-406

88. Simpson PJ, Stanton C, Fitzgerald GF, Ross RP (2005) Intrinsic tolerance of Bifidobacterium species to heat and oxygen and survival following spray drying and storage. J Appl Microbiol 99:493-501

89. Su P, Henriksson A, Mitchell H (2007) Prebiotics enhance survival and prolong the retention period of specific probiotic inocula in an in vivo murine model. J Appl Microbiol 103: 2392-2400

90. Teixeira P, Castro H, Kirby R (1994) Inducible thermotolerance in Lactobacillus bulgaricus. Lett Appl Microbiol 18:218-221

91. Turroni F, Bottacini F, Foroni E, Mulder I, Kim JH, Zomer A, Sánchez B, Bidossi A, Ferrarini A, Giubellini V, Delledonne M, Henrissat B, Coutinho P, Oggioni M, Fitzgerald GF, Mills D, Margolles A, Kelly D, van Sinderen D, Ventura M (2010) Genome analysis of Bifidobacterium bifidum PRL2010 reveals metabolic pathways for host-derived glycan foraging. Proc Natl Acad Sci U S A (in press) 
92. Van de Guchte M, Serror P, Chervaux C, Smokvina T, Ehrlich SD, Maguin E (2002) Stress responses in lactic acid bacteria. Antonie van Leeuwenhoek 82:187-216

93. Ventura M, Canchaya C, Van Sinderen D, Fitzgerald GF, Zink R (2004) Bifidobacterium lactis DSM 10140: identification of the atp (atpBEFHAGDC) operon and analysis of its genetic structure, characteristics, and phylogeny. Appl Environ Microbiol 70:3110-3121

94. Ventura M, Canchaya C, Zhang Z, Bernini V, Fitzgerald GF, van Sinderen D (2006) How high G + C Gram-positive bacteria and in particular bifidobacteria cope with heat stress: protein players and regulators. FEMS Microbiol Rev 30:734-759

95. Ventura M, Canchaya C, Zhang Z, Fitzgerald GF, van Sinderen D (2007) Molecular characterization of $h s p 20$, encoding a small heat shock protein of Bifidobacterium breve UCC2003. Appl Environ Microbiol 73:4695-4703

96. Ventura M, Canchaya C, Zink R, Fitzgerald GF, van Sinderen D (2004) Characterization of the groEL and groES loci in Bifidobacterium breve UCC2003: genetic, transcriptional, and phylogenetic analyses. Appl Environ Microbiol 70:6197-6209

97. Ventura M, Canchaya C, Bernini V, Del Casale A, Dellaglio F, Neviani E, Fitzgerald GF, van Sinderen D (2005) Genetic characterization of the Bifidobacterium breve UCC2003 hrcA locus. Appl Environ Microbiol 71:8998-9007

98. Ventura M, Fitzgerald GF, van Sinderen D (2005) Genetic and transcriptional organization of the clpC locus in Bifidobacterium breve UCC2003. Appl Environ Microbiol 71:6282-6291

99. Ventura M, Kenny JG, Zhang ZD, Fitzgerald GF, van Sinderen D (2005) The clpB gene of Bifidobacterium breve UCC2003: transcriptional analysis and first insights into stress induction. Microbiology-SGM 151:2861-2872

100. Ventura M, Zhang ZD, Cronin M, Canchaya C, Kenny JG, Fitzgerald GF, van Sinderen D (2005) The ClgR protein regulates transcription of the $c l p \mathrm{P}$ operon in Bifidobacterium breve UCC2003. J Bacteriol 187:8411-8426

101. Von Ah U, Mozzetti V, Lacroix C, Kheadr EE, Fliss I, Meile L (2007) Classification of a moderately oxygen-tolerant isolate from baby faeces as Bifidobacterium thermophilum. BMC Microbiol 7:79

102. Watson D, Sleator RD, Hill C, Gahan CGM (2008) Enhancing bile tolerance improves survival and persistence of Bifidobacterium and Lactococcus in the murine gastrointestinal tract. BMC Microbiol 8:176

103. Yang Y, Chen M, Liao C (2001) New isolated Bifidobacterium mutant strains tolerant to oxygen, bile salts and gastric acid, which can pass through the stomach with increased survivability, useful in foods. Patent number US6306638-B1

104. Yuan J, Wang B, Sun Z, Bo X, Yuan X, Zhao H, Du X, Wang F, Jiang Z, Zhang L, Jia L, Wang Y, Wei K, Wang J, Zhang X, Sun Y, Huan L, Zeng M (2008) Analysis of host-inducing proteome changes in Bifidobacterium longum NCC2705 grown in vivo. J Proteome Res 7:375-385

105. Zomer A, Fernandez M, Kearney B, Fitzgerald GF, Ventura M, van Sinderen D (2009) An interactive regulatory network controls stress response in Bifidobacterium breve UCC2003. J Bacteriol 191:7039-7049 